STUDI

FRANCESI

\section{Studi Francesi}

Rivista quadrimestrale fondata da Franco Simone

174 (LVIII | III) | 2014

Varia

\title{
Aa. Vv, Lectures d'Étienne Jodelle. Didon se sacrifiant, sous la direction de Emmanuel Buron et Olivier Halévy
}

Maurizio Busca

\section{(2) OpenEdition}

Journals

\section{Edizione digitale}

URL: http://journals.openedition.org/studifrancesi/1114

DOI: $10.4000 /$ studifrancesi. 1114

ISSN: 2421-5856

\section{Editore}

Rosenberg \& Sellier

\section{Edizione cartacea}

Data di pubblicazione: 1 novembre 2014

Paginazione: 581

ISSN: 0039-2944

\section{Notizia bibliografica digitale}

Maurizio Busca, «Aa. Vv, Lectures d'Étienne Jodelle. Didon se sacrifiant, sous la direction de Emmanuel Buron et Olivier Halévy », Studi Francesi [Online], 174 (LVIII | III) | 2014, online dal 01 novembre 2014, consultato il 18 septembre 2020. URL : http://journals.openedition.org/studifrancesi/1114; DOI : https://doi.org/10.4000/studifrancesi. 1114

Questo documento è stato generato automaticamente il 18 settembre 2020.

\section{cc) (†) $\odot$}

Studi Francesi è distribuita con Licenza Creative Commons Attribuzione - Non commerciale - Non opere derivate 4.0 Internazionale. 


\section{Aa. Vv, Lectures d'Étienne Jodelle. Didon se sacrifiant, sous la direction de Emmanuel Buron et Olivier Halévy}

Maurizio Busca

\section{NOTIZIA}

AA. VV., Lectures d'Étienne Jodelle. Didon se sacrifiant, sous la direction de Emmanuel BURON et Olivier HALÉVY, Rennes, Presses Universitaires de Rennes, 2013 («Didact Français»), pp. 235.

Opera fondamentale del teatro rinascimentale francese, ma fino a poco tempo fa trascurata dalla ricerca, la Didon se sacrifiant di Jodelle è recentemente divenuta oggetto di intensi studi grazie alla sua iscrizione nel programma di Agrégation 2014. Rivolta in primo luogo ai candidati al concorso, la presente raccolta riunisce nove contributi, oltre a una Introduction ad opera dei curatori (pp. 9-32) e a un'appendice che riporta numerosi errata dell'edizione Champion 2002, molti dei quali non segnalati dall'editore (pp. 227-233). Il taglio talvolta didattico nulla toglie all'interesse degli articoli, suddivisi in tre sezioni tematiche: stilistica e retorica; drammaturgia; filosofia.

2 Prima parte («Écritures tragiques»): Stéphane MACÉ, "Que ne vient on changer à ma mort ma langueur?»: quelques remarques sur l'emploi des énoncés interrogatifs dans "Didon se sacrifiant", pp. 35-46; John NASSICHUK, «Mais pourquoy tant de mots?»: sur quelques emplois de la sentence dans "Didon se sacrifiant", pp. 47-64; Francis GOYET, La rhétorique de Didon dans l'acte II: l'exprobatio des v. 851-952, pp. 65-96; Olivier HALÉVY, «Le courroux fait la langue»: écriture pathétique et style maniériste dans "Didon se sacrifiant", pp. 97-116. Seconda parte («Dramaturgie tragique»): Nina HUGoT, «Les deux peuples divers»: le double chœeur dans "Didon se sacrifiant", pp. 119-137; Emmanuel BURON, La Renaissance de la 
tragédie ou le spectacle de la parole, pp. 139-168; Emmanuel BURON, Scénographie de la parole et spectacle sacrificiel dans "Didon se sacrifiant", pp. 169-178; Enrica ZANIN, Didon et ses sœurs: la tragédie de Jodelle au prisme des adaptations modernes, pp. 179-188. Terza parte («Philosophie tragique»): François coRnilliat, Le jugement d'Énée ou la tragédie du «moindre mal», pp. 191-223.

I contributi della prima parte prendono in esame la lingua della Didon, mettendone in luce alcune peculiarità: l'originalità della scrittura di Jodelle si rivela anche nell'appropriazione e nell'attualizzazione di strutture retoriche classiche. MACÉ analizza i differenti impieghi degli enunciati interrogativi, che ricorrono con singolare frequenza nella pièce in questione, mentre oggetto del contributo di NASsichuK è la sententia, altro tratto stilistico caratteristico della Didon. Per rilevare ulteriori elementi distintivi dello stile di Jodelle, HALÉVY istituisce un confronto fra i dialoghi della Didon e quelli di quattro tragedie coeve. GOYET studia invece un brano isolato, comparandolo con i versi virgiliani da cui è tratto e rilevando la consapevolezza retorica di Jodelle, per concludere con alcune osservazioni sulla teologia del personaggio di Didon. La seconda parte del volume tocca questioni legate alla drammaturgia. HUGoT indaga l'uso originale del coro: scisso in due gruppi contrapposti, il suo ruolo tradizionale nel quadro della pièce viene innovato dal drammaturgo. Il primo dei due articoli di BURON, già pubblicato nel 1995, studia il mutare del valore della parola dalla Cleopatre captive alla Didon se sacrifiant: si assiste al passaggio da una drammaturgia divisa tra visione e dizione ad una drammaturgia che accorda piena fiducia alla sola forza della parola. Partendo da questa prima analisi, nel secondo l'A. rileva la dimensione centrale del tema del sacrificio, vera chiave di volta della Didon e di diverse altre tragedie della metà del Cinquecento. Il contributo di ZANIN si articola intorno ad una comparazione fra la pièce di Jodelle e le numerose altre tragedie europee dei secoli XVI e XVII che mettono in scena il personaggio di Didone. Infine coRnilLIAT (il cui articolo costituisce la terza parte della raccolta) definisce i caratteri di quella philosophie du moindre mal sottesa alla Didon e a parte della produzione, non solo drammatica, di Jodelle. 